\title{
Ozone and Aerosol Influence on Ultraviolet Radiation on the East Coast of the Brazilian Northeast
}

\author{
Alexandre Boleira Lopo ${ }^{1 *}$, Maria Helena Constantino Spyrides ${ }^{1,2^{*}}$, Paulo Sérgio Lucio ${ }^{1,2}$, Javier Sigró ${ }^{3}$ \\ ${ }^{1}$ Programa de Pós-Graduação em Ciências Climáticas-PPGCC, Natal, Brasil \\ ${ }^{2}$ Departamento de Estatística, Universidade Federal do Rio Grande do Norte, Natal, Brasil \\ ${ }^{3}$ Department of Geography, Centre for Climate Change (C3), University Rovira i Virgili, Tarragona, Spain \\ Email: *alexandrelopo@hotmail.com, *spyrides@ccet.ufrn.br
}

Received November 1, 2013; revised November 26, 2013; accepted December 3, 2013

Copyright (C) 2014 Alexandre Boleira Lopo et al. This is an open access article distributed under the Creative Commons Attribution License, which permits unrestricted use, distribution, and reproduction in any medium, provided the original work is properly cited. In accordance of the Creative Commons Attribution License all Copyrights (C) 2014 are reserved for SCIRP and the owner of the intellectual property Alexandre Boleira Lopo et al. All Copyright (C) 2014 are guarded by law and by SCIRP as a guardian.

\section{ABSTRACT}

The purpose of this research is to determine the influence of Total Ozone and Aerosols about variability of Ultraviolet Radiation (UV) in the east coast of the Northeastern region of Brazil through measures from multispectral sensor GUV (Ground-based Ultraviolet Radiometer). The methodology consisted of descriptive study and cluster analyses using data of UV in channels UVB $(305 \mathrm{~nm})$ and UVA $(320 \mathrm{~nm}, 340 \mathrm{~nm}$ and $380 \mathrm{~nm})$ and data of UV index, Total Ozone, Aerosol, Global Solar Radiation, Cloudiness and Wind. The results for city of Natal indicated that an annual event occurs in September/October which stabilizes the UV or UV Index when Total Ozone levels reach their annual maximum. This event is influenced by marine Aerosol that is found on mainland at a higher concentration in September due to greater Wind intensity and their southeasterly direction (sea for land). The cluster analysis using the variables above allowed us to detect three different groups: the first group is formed by Natal, Recife and João Pessoa and so determined that this event occurs in these three cities; the second group is formed by Maceió, Aracaju and Salvador and the third group includes only Fortaleza and had different results.

\section{KEYWORDS}

\section{Cluster Analyses; Radiometer; Global Solar Radiation; Cloudiness; Annual Event of Spring from UV}

\section{Introduction}

The Ultraviolet Radiation (UV) has wavelengths $(\lambda)$ between 100 and $400 \mathrm{~nm}$ and can be classified according to the effects on human health and the environment in spectral ranges: UVA, $315 \mathrm{~nm}$ to $400 \mathrm{~nm}$, UVB, at $280 \mathrm{~nm}$ to $315 \mathrm{~nm}$ and UVC, 100 to $280 \mathrm{~nm}$ [1]. The radiation in the UVC range corresponds to approximately $1 \%$ of solar emissions and does not reach the earth's surface due to the strong absorption in the atmosphere by ozone and molecular oxygen $[2,3]$.

The spectral band of UV radiation $(280-400 \mathrm{~nm})$ that reaches the Earth's surface is affected mainly by the atmosphere (absorption of ozone, cloudiness, aerosols and pollutants in the troposphere) and the reflectivity of the ground, which is composed in large part of UVA

*Corresponding authors.
(90\%) and to a lesser degree of UVB (10\%) $[2,4,5]$.

The UV causes various effects on terrestrial and aquatic ecosystems and inorganic materials [1,6]. Despite some beneficial effects [7], an inequivocal and prolonged human exposure to UV can result in adverse effects, which may be both acute and chronic [6]. The negative effects are manifested predominantly on the skin by means of cancer, burns and erythema [8] and premature aging, however, they may affect the eyes [9] and immune system [10].

Skin cancer is characterized by different aspects of exposure: non-melanoma skin cancer or not malignant (NMSC) and melanoma skin cancer or malignant (MSC). There are estimates that NMSC (134,000 new cases) is the most frequent in the Brazilian population and corresponds to $25.7 \%$ of all tumors [11]. In comparison, MSC causes a high fatality rate but occurs less frequently. In 
the capitals of the Northeastern Region of Brazil (NEB), for men, NMSC is the second most frequent type of cancer (34.69/100 thousand) and the most frequent for women (31.17/100 thousand) [11].

The Ultraviolet Radiation index (UV index) is an important resource that increases public awareness of the risks of overexposure to the sun. Its function is to describe the level or intensity of UV on the surface of the planet, and is used as a warning to people to protect themselves from UV. This index is an open-ended scale, universally applicable to any individual of the population, without regard to their skin color $[1,12]$.

$\mathrm{UV}$ in the atmosphere is attenuated by processes such as absorption or scattering by Total Ozone column (Total Ozone) and aerosol particles. The amount of Ozone in the atmosphere is recovering as a result of the Montreal Protocol in force since 1989 [2]. Despite the recovery of Total Ozone, UV in high latitudes is predicted to increase in the near future [12-14]. In the more populated regions, the highest increase of UV has been found in the Southern Hemi- sphere, such as in NEB, in latitudes from -20 to 0 [14].

The presence of Aerosols in atmosphere can be observed through a parameter called Aerosol Optical Depth (AOD). This variable is an extinction measurement (no dimension) of radiation and its interaction with aerosol particles in atmosphere, mainly due to the processes of spreading and absorption [15-17].

This article seeks to collaborate and understand these issues and aims to conduct a descriptive study and analytical (cluster analyses) of variability of UV and UV index in relation to Total Ozone and relevant variables for the state capitals of the east coast of Northeastern Brazil.

\section{Material and Methods}

\subsection{Study Area}

The study area covers the coastal region on the eastern and northern coasts of Northeastern Brazil (NEB) and in capital of states of Ceará (Fortaleza), Rio Grande do Norte (Natal), Paraíba (João Pessoa), Pernambuco (Recife), Alagoas (Maceió), Sergipe (Aracaju) and Bahia (Salvador) (Figure 1).

The measurement of Ultraviolet Radiation (UV) was based on a Radiometer located in Natal $\left(5^{\circ} 48^{\prime} \mathrm{S}, 35^{\circ} 12^{\prime} \mathrm{W}\right)$, which is thus regarded as the city of reference for this study from UV.

The city of Natal, capital of Rio Grande do Norte (RN), is located in the NEB on the eastern coast of South America, between the sea and the right bank of River Potengi, where they reside 853,928 inhabitants in an area of $17.298 \mathrm{~km}^{2}$ [18]. Its proximity to the equator determines great luminosity and high levels of solar radiation. The trajectory of the Sun varies with solar zenith

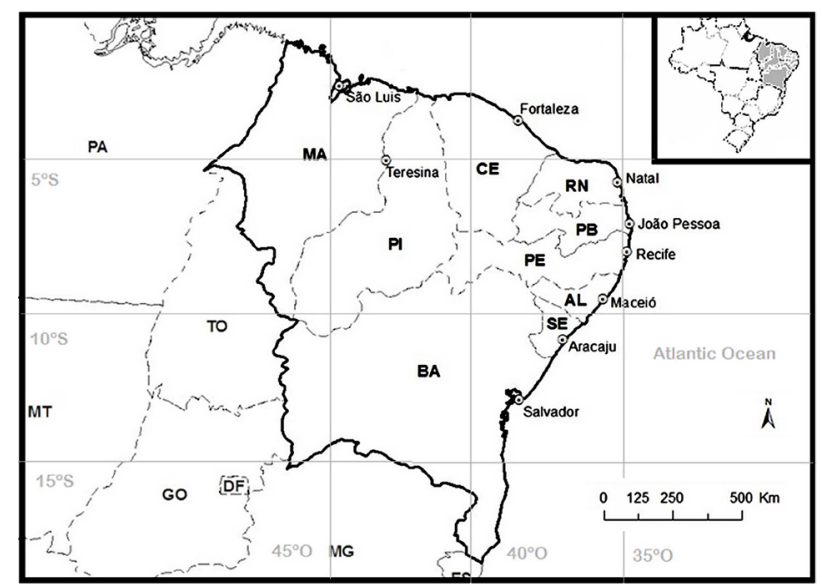

Figure 1. Location of Natal in Rio Grande do Norte and capitals of the states of Northeast Brazil.

angle (SZA) between $65^{\circ}$ - 90 [19]. The average annual temperature is $26^{\circ} \mathrm{C}$ and relative humidity and $77.3 \%$ [20].

The RN is near the intertropical convergence zone that receives the trade winds, so the climate in its capital is hot and dry, except during the rainy season, when it is hot and humid. The rainy season is result of so-called easterly waves and occur between the months of April to July, with predominance in Abril with approximately 265 mm [20,21]. In Natal city also operate the sea breezes system, resulting from temperature differences between the land and sea surfaces, causing increased precipitation at night $[22,23]$ and wavy perturbations of the trade winds, consisting of unstable air masses, deep and moist causing rapid and moderate rains in NEB coastal lasting up to 48 hours and 18 - 24 hours intervals. The strongest winds are characteristic of September, and in April the winds are weakest $[20,24]$.

\subsection{Data}

The hourly and daily data (2001-2009) of UV in channel UVB (305 nm), channels UVA (320 nm, $340 \mathrm{~nm}$ and 380 $\mathrm{nm})$ and UV index were measured on the surface by the Ground-based Ultraviolet Radiometer (GUV), Model 511-C. The irradiance is given in units of $\mu \mathrm{Wcm}{ }^{-2} \cdot \mathrm{nm}^{-1}$ and was measured at four channels and integrated to convert the measurements on UV index. The equipment was installed in Laboratory of Tropical Environmental Variables of National Institute of Spatial Research (INPE/ CRN/LAVAT) in Natal city. The daily maximums of the UV and UV index were obtained from 11:00 am to 1:00 pm, independent of sky conditions.

A set of daily data (2001-2009) of Total Ozone in Dobson Units (DU) was obtained at the National Centers for Environmental Prediction/National Oceanic and Atmospheric Administration (NCEP/NOAA/USA), with grid 
resolution $2.5^{\circ} \times 2.5^{\circ}$ [25], available at

www.esrl.noaa.gov.

The daily data (2007-2009) of Global Solar Radiation (GSR) $\left(\mathrm{Wm}^{-2}\right.$ ) was obtained from Radiometer in Solarimetric Station of INPE/CRN/LAVAT. The data represents the average value of GSR from 11:00 am - 12:00 pm.

The monthly data of Cloudiness (2001-2009) in range 0 - 10 were obtained from database of meteorological data for Teaching and Research (BDMEP/INMET) [20] and data of intensity ( $\mathrm{ms}^{-1}$ ) and Wind direction (degrees) were obtained from the Climate Standard of the National Institute of Meteorology of Brazil [20], available at www.inmet.gov.br.

The Aerosol Optical Depth (AOD), measured in the wavelength of $0.55 \mu \mathrm{m}$ by Moderate Resolution Imaging Spectroradiometer (MODIS/AQUA) (2004-2009) was obtained in the division of environmental satellites of Center for Weather Forecasting and Climate Studies (CPTEC/ INPE/BRAZIL) through the Environmental Information System (SISAM), available in http://sisam.cptec.inpe.br.

\subsection{UV Index-Formulation}

The UV index was formulated by the International Commission on Illumination (CIE) based on the reference spectrum of action erythema (ISO 17166:1999/CIE S 007/E-1998) and describes the intensity of UV in relation to its photo biological effect [26]. The UV index is defined by Equation (1):

$$
\text { UV Index }=\mathrm{K}_{e r} \int_{250 \mathrm{~nm}}^{400 \mathrm{~nm}} \mathrm{E}_{\lambda} \mathrm{S}_{\mathrm{er}}(\lambda) \mathrm{d} \lambda,
$$

in which $E_{\lambda}$ is the spectral irradiance expressed in $\mathrm{Wm}^{-2} \cdot \mathrm{nm}^{-1}$ to the wavelength $\lambda$ and $\mathrm{d}_{\lambda}$ it is the wavelength range used in the integral calculus. Ser $(\lambda)$ is the reference action spectrum erythema and $\mathrm{K}_{\mathrm{er}}$ is a constant equal to $40 \mathrm{~m}^{2} \cdot \mathrm{W}^{-1}$.

The UV index is standardization of erythema irradiance $\left(\mathrm{S}_{\mathrm{er}}\right)$ by means of a numerical scale, such that $1 \mathrm{UV}$ index $=0.025 \mathrm{Wm}^{-2}[1,12]$. The UV index is divided into categories associated with the colors (Table 1), being proposed by the World Health Organization (WHO)

Table 1. Relationship between UV index and category of risk to humans.

\begin{tabular}{ccc}
\hline Category of risk & Range of UV index & Color \\
\hline Low & 0 to 2 & Green \\
Moderate & 3 to 5 & Yellow \\
High & 6 to 7 & Orange \\
Very High & 8 to 10 & Red \\
Extreme & $>11$ & Violet \\
\hline
\end{tabular}

Source: [1]. and World Meteorological Organization (WMO) to facilitate the understanding of the population about the effects of UV on human beings [1].

The precautions to be taken by the individual, in accordance with this classification, are suggested by the WHO and refer to the use of hats, clothes, sunglasses, sunscreen, and umbrellas or even to stay inside the house. The UV index is an integer and dimensionless representing the maximum daily value in a horizontal surface [1].

\subsection{Hierarchical Cluster Analysis}

Considering the limitations of UV data acquisition on the surface (these measurements were restricted to the city of Natal) and aiming to expand the analysis to the total area to be investigated, a cluster analysis of available variables was used to study the variability of the UV surface, highlighting the Total Ozone, AOD, intensity and Wind direction.

A Cluster Analysis is a multivariate form of analysis in which a technique for building clusters groups together similar measurements (metric) of distance and determines a connection between the clusters [27].

The Central idea of the clustering of data points is the idea of distance. Clusters should be composed of points separated by small distances, relative to the distances between clusters. The most intuitive and commonly used distance measure in cluster analysis is the Euclidean distance in the K-dimensional space of the data vectors [27]. A more general alternative is the weighted Euclidean distance between two vectors $\mathrm{x}_{\mathrm{i}}$ and $\mathrm{x}_{\mathrm{j}}$,

$$
\mathrm{d}_{\mathrm{i}, \mathrm{j}}=\left[\sum_{\mathrm{k}=1}^{\mathrm{K}} \mathrm{w}_{\mathrm{k}}\left(\mathrm{x}_{\mathrm{i}, \mathrm{k}}-\mathrm{x}_{\mathrm{j}, \mathrm{k}}\right)^{2}\right]^{1 / 2} .
$$

For $\mathrm{w}_{\mathrm{k}}=1$ for each $\mathrm{k}=1, \cdots, \mathrm{K}$, Equation (2) reduces to the ordinary Euclidean distance. A yet more general form of Equation (2) is the Minkowski metric,

$$
\mathrm{d}_{\mathrm{i}, \mathrm{j}}=\left[\sum_{\mathrm{k}=1}^{\mathrm{K}} \mathrm{w}_{\mathrm{k}}\left(\mathrm{x}_{\mathrm{i}, \mathrm{k}}-\mathrm{x}_{\mathrm{j}, \mathrm{k}}\right)^{\lambda}\right]^{1 / \lambda}, \lambda \geq 1 .
$$

The weights $\mathrm{w}_{\mathrm{k}}$ can equalize the influence of variables with incommensurate units. For $\lambda=2$, Equation (3) reduced to the weighted Euclidean distance in Equation (2). For $\lambda=1$, Equation (3) is known as the city-block distance [27]. In this study was used the Minkowski metric.

They were used as linkage criterion in Ward's hierarchical method study. Ward's method suggested a general agglomerative hierarchical clustering procedure, in which the criterion for choosing the pair of clusters to merge at each step is based on the optimal value of an objective function [28]. 


\section{Results and Discussions}

\section{UV Variability in Natal-RN}

The average irradiance of UV radiation for each wavelength and variables analyzed in Natal are shown in Table 2 and Figure 2.

After calculating the channel $305 \mathrm{~nm}$ (UVB) in Table 2 , a $5.1 \%$ reduction was identified in the average irradiance for the second semester compared to the first (in UV index a reduction of 5.3\%). During the second semester, there was a greater absorption of UVB due to a $3.8 \%$ increase in the average level of Total Ozone. Table 2 shows the values per semester.

Table 2. Irradiance for wavelength of $\mathbf{U V}$ and variables analyzed in Natal. Monthly data.

\begin{tabular}{|c|c|c|c|c|c|c|}
\hline \multirow{2}{*}{ Period } & \multicolumn{4}{|c|}{ Wavelength (nm) } & \multicolumn{2}{|c|}{ UV Index } \\
\hline & 305 & 320 & \multicolumn{2}{|c|}{340} & 380 & $\mathrm{Nd}$ \\
\hline Jan & 8.3 & 36.2 & \multicolumn{2}{|c|}{63.4} & 85.2 & 11.7 \\
\hline Feb & 9.2 & 38.3 & \multicolumn{2}{|c|}{66.3} & 88.9 & 12.6 \\
\hline Mar & 9.0 & 38.0 & \multicolumn{2}{|c|}{65.5} & 87.9 & 12.5 \\
\hline Apr & 8.1 & 34.9 & \multicolumn{2}{|c|}{60.3} & 81.0 & 11.3 \\
\hline May & 6.9 & 31.1 & \multicolumn{2}{|c|}{53.7} & 73.9 & 10.9 \\
\hline Jun & 6.0 & 27.9 & \multicolumn{2}{|c|}{50.9} & 70.2 & 8.7 \\
\hline $1^{\text {st }}$ Sem & 7.9 & 34.4 & \multicolumn{2}{|c|}{60.0} & 81.2 & 11.3 \\
\hline Jul & 6.0 & 28.6 & \multicolumn{2}{|c|}{52.0} & 71.4 & 8.7 \\
\hline Aug & 6.8 & 32.4 & \multicolumn{2}{|c|}{57.1} & 77.9 & 10.0 \\
\hline Set & 7.3 & 34.5 & \multicolumn{2}{|c|}{59.7} & 82.3 & 10.4 \\
\hline Out & 8.3 & 37.4 & \multicolumn{2}{|c|}{66.0} & 88.3 & 11.8 \\
\hline Nov & 8.3 & 37.9 & \multicolumn{2}{|c|}{65.7} & 87.9 & 11.9 \\
\hline Dec & 8.0 & 36.1 & 63 & & 85.6 & 11.3 \\
\hline $2^{\mathrm{st}}$ Sem & 7.5 & 34.5 & 60 & & 82.2 & 10.7 \\
\hline Annual & 7.7 & 34.4 & 60 & & 81.7 & 11.0 \\
\hline Period & $\begin{array}{c}\text { Total } \\
\text { Ozone }\end{array}$ & $\begin{array}{c}\text { AOD } \\
0.55 \mu \mathrm{m}\end{array}$ & & ind & Cloudiness & GSR \\
\hline & DU & $\mathrm{Nd}$ & $\mathrm{ms}^{-1}$ & degrees & $(0-10)$ & $\mathrm{Wm}^{-2}$ \\
\hline Jan & 260.8 & 0.19 & 4.4 & 117 & 7.2 & 931.1 \\
\hline Feb & 260.8 & 0.20 & 4.2 & 121 & 7.2 & 960.1 \\
\hline Mar & 263.5 & 0.21 & 3.6 & 122 & 7.2 & 928.7 \\
\hline Apr & 260.7 & 0.16 & 3.2 & 135 & 7.3 & 748.4 \\
\hline May & 257.1 & 0.18 & 3.9 & 146 & 7.0 & 652.1 \\
\hline Jun & 259.4 & 0.15 & 4.2 & 149 & 7.4 & 542.3 \\
\hline $1^{\text {st }}$ Sem & 260.4 & 0.18 & 3.9 & 132 & 7.2 & 793.8 \\
\hline Jul & 265.5 & 0.18 & 4.4 & 152 & 6.7 & 568.7 \\
\hline Aug & 270.6 & 0.20 & 5.2 & 145 & 6.7 & 650.5 \\
\hline Set & 278.4 & 0.22 & 5.3 & 136 & 6.6 & 785.5 \\
\hline Out & 276.2 & 0.18 & 5.2 & 124 & 6.5 & 976.9 \\
\hline Nov & 268.8 & 0.15 & 4.9 & 118 & 6.6 & 994.1 \\
\hline Dec & 262.2 & 0.17 & 4.7 & 115 & 7.0 & 972.1 \\
\hline $2^{\text {st }}$ Sem & 270.3 & 0.18 & 5.0 & 132 & 6.7 & 824.6 \\
\hline Annual & 265.3 & 0.18 & 4.4 & 132 & 7.0 & 809.2 \\
\hline
\end{tabular}

Source: INPE/INMET/NCEP-NOAA/MODIS. Nd: no dimension.
UV 305 nm

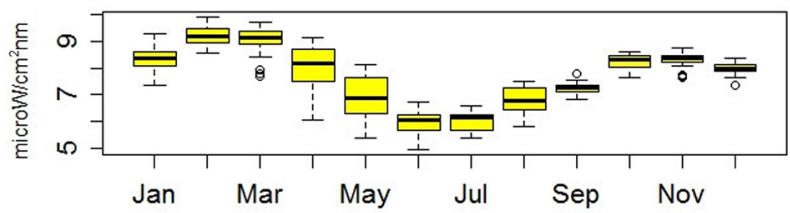

UV $320 \mathrm{~nm}$

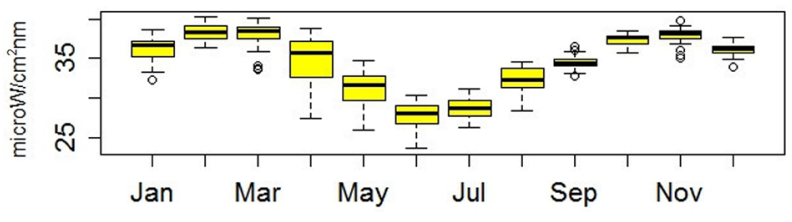

UV $340 \mathrm{~nm}$

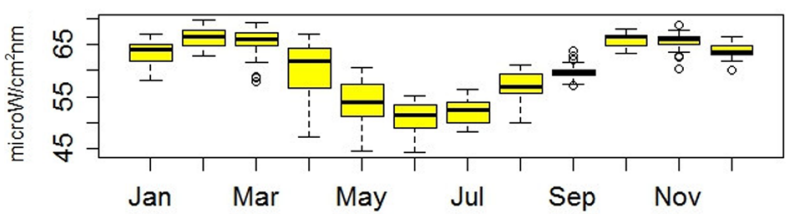

UV $380 \mathrm{~nm}$
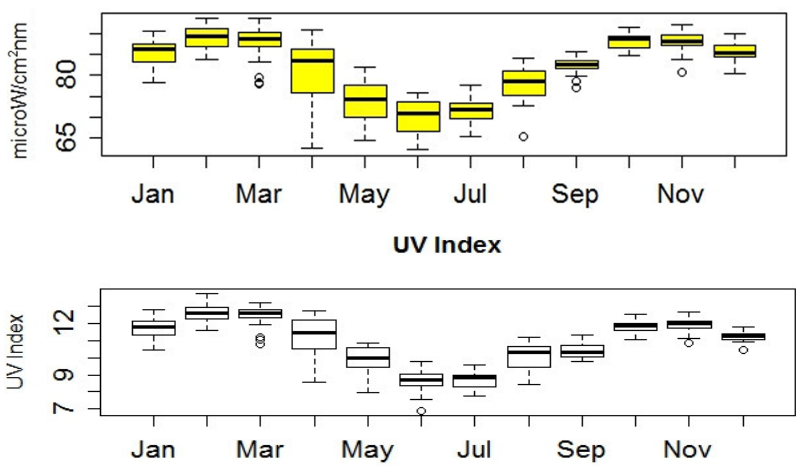

Total Ozone

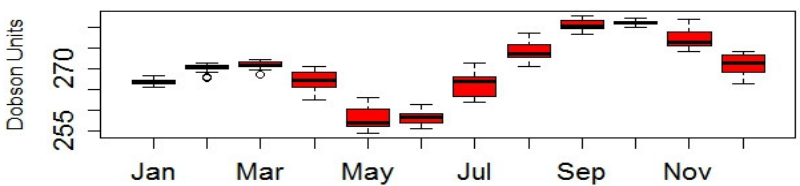

Figure 2. Irradiance for wavelength of $\mathrm{UV}\left(\mu \mathrm{Wcm} \mathrm{cm}^{-2} \cdot \mathrm{nm}^{-1}\right)$, UV Index and Total ozone (Dobson Units) annual variability for Natal. Source: INPE/CRN/LAVAT.

In Table 2 it can be observed that UV index in Natal reached a level "extreme" $(>11)$ for seven months of the year, predominantly between spring and summer. February and March presented the highest average monthly indices (between 12 and 13). June and July showed the lower 
indices around 9.0, a level which is still considered as "very high" (8 - 10). The first annual maximum of 12.6 occurred in February. In second semester occurred in November, with 11.9.

This characteristic can be explained because the sun's stations near to Tropic of Capricorn reach the angle solar zenith near $0^{\circ}\left(\mathrm{SZA} \approx 0^{\circ}\right)$ twice a year and the stations of observations register two annual ceilings, one in the summer, in February, and the other in the spring, in October [29], in Natal occurred in November. The UV index annual average is 11 (Table 2), similar to that found by [19].

In Figure 2, a stabilization of the UV index levels and wavelengths $305 \mathrm{~nm}$ (UVB) was identified in September, however, this attenuation is slightly lower for 320, 340 and $380 \mathrm{~nm}$ (nearest visible radiation) due to lower absorption by Ozone in these UVA channels. In addition to the proposed objectives, this study sought to analyze the causes of this behavior identified in September, referred to as the Annual Event of Spring from UV (AES-UV), so called due occur at the beginning and during the spring in the southern hemisphere.

The AES-UV takes place between September and October, since the Pearson correlation coefficient for this period indicated an inverse relationship between Total Ozone and UV index corresponding to $-0.5 \%$ or $-50 \%$. Figure 3 shows (simultaneously) the annual variability of UV Index and Total Ozone. In this figure, one can observe the AES-UV in September and October days 244304 when the Total Ozone reaches a maximum annual.

To explain AES-UV, the variability of GSR was first taken into consideration. The GSR (directly associated with the sun elevation or SZA) determines the greatest influence on the UV index [1,4]. Figure 4 shows the annual variability of the GSR to the city of Natal. It was identified that no occurs attenuation of GSR during UVAES, thus is not associated with the event.

It was verified that the stabilization of UV index

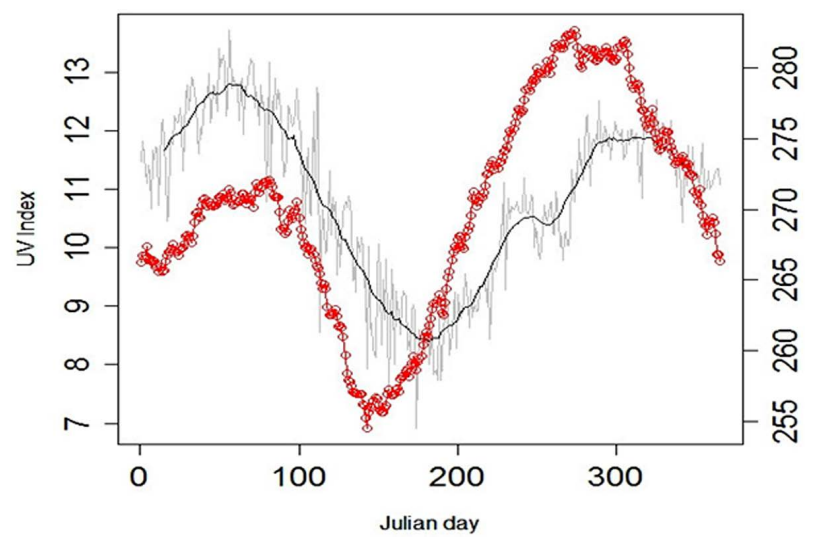

Figure 3. Simultaneous graph of variability annual UV Index (left scale) and filtering (moving average) and Total Ozone (red points and right scale). Source: INPE/CRN/ LAVAT and NCEP/NOAA.

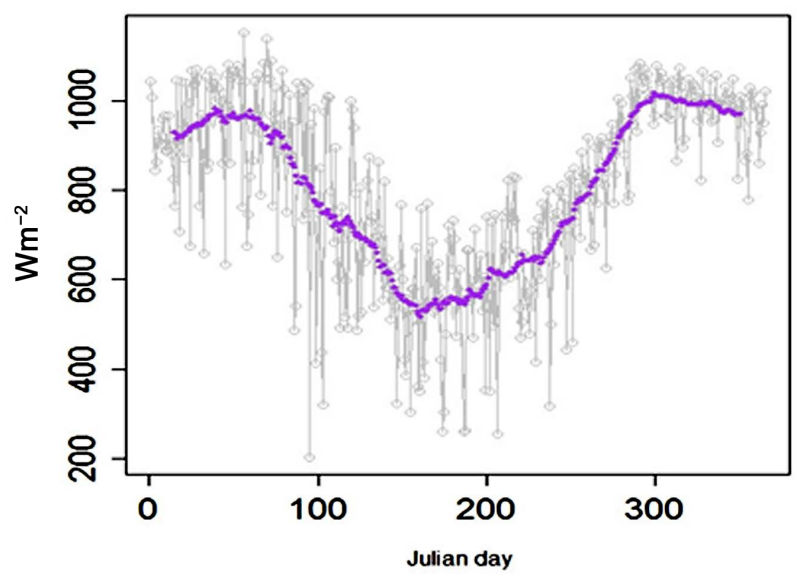

Figure 4. Variability annual Global Solar Radiation (GSR) $\left(\mathrm{Wm}^{-2}\right)$ from 11:00-12:00 pm and filtering (moving average). Source: INPE/CRN/LAVAT.

observed in AES-UV couldn't be associated with cloudiness, because at this time there are fewer clouds (Table 2). Excluding the GSR and Cloudiness, AES-UV can be explained by the highest Total Ozone in September/October (highlighted values in Table 2).

The annual variability of Total Ozone in the atmosphere varies periodically and conversely (approximately) to the increase in available solar radiation [30]. The temperature increase caused by absorption of solar radiation generates instabilities in the photochemical equilibrium in the stratosphere, which accounts for about $90 \%$ of the integrated Ozone. These high levels lead to the reduction of its production, so that the maximum content of Ozone is observed in spring with a decrease in summer and an increase again in the autumn [30-32].

Despite the strong signal of GSR in areas near to equator, it has a lesser range to influence on the variability of UV index [30]. The city of Natal is located at low latitude, so the influence of Total Ozone in variability of UV appears more clearly. During the spring and autumn equinoxes (September and March respectively) in the Southern Hemisphere, when the elevation of the sun is almost the same, one can compare the oscillations of the UV index in relation to Ozone content in periods of very similar radiation solar intensity [30,31]. The average difference of 14.9 DU (278.4 - 263.5 in Table 2) was observed between the two equinoxes. This resulted in UV index values of 12.5 and 10.4 respectively. This difference represents a change in the scale of "extreme" to "very high".

After the AES-UV, in December, if one only considered the reduction of Total Ozone, logically it would result in an increase of UV index, however the opposite occurred. This fact is associated with the reduction of GSR (Table 2). This behavior can be observed by measurements at various locations in the Southern Hemisphere [33-35]. 
Besides the Total Ozone, UV is attenuated by other processes, such as the absorption of aerosol particles [3638]. The AOD in Natal reaches its highest value during the month of September (0.22 in Table 2). This may contribute to the reduction in the UV index during the AES-UV.

The high AOD is related to the intensity of Winds (trade Winds) that have the highest average magnitude in September at $5.3 \mathrm{~ms}^{-1}$ (Table 2) and their predominant southeasterly direction [20]. The Wind direction may explain the higher concentration of marine aerosol, since the city is located on the east coast of NEB. A physicalchemical study was not conducted and thus the type of aerosols cannot be confirmed. It is worth mentioning that the variations exercised by the aerosols are lower than those related to the variations of the Total Ozone and GSR $[12,39]$. Figure 5 shows the Wind and AOD in annual variability in Natal.

The Cluster Analysis indicated three groups (Figure 6). The first group was defined by Natal, João Pessoa and Recife.

The similarity in relation to Total Ozone, Wind and AOD characteristics (Figure 7) shows that the AES-UV occurs identically in these cities.

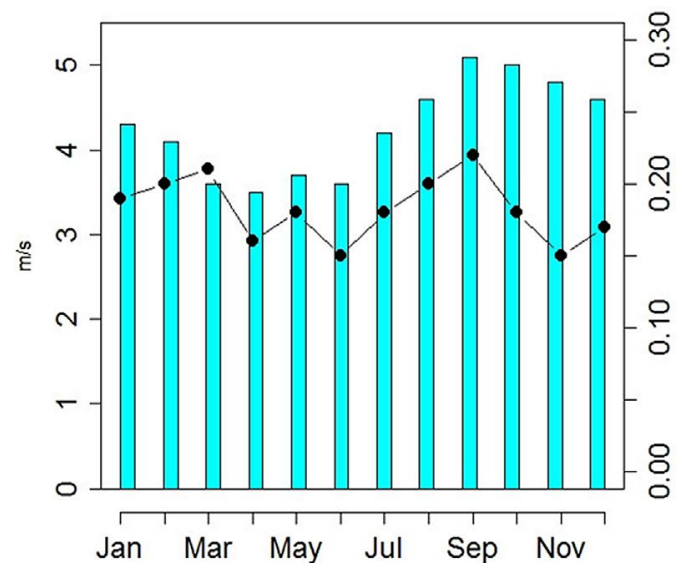

Figure 5. Barplot of Wind intensity (graphical bars) and AOD (points and right scale) in Natal. Source: INMET and MODIS/AQUA.

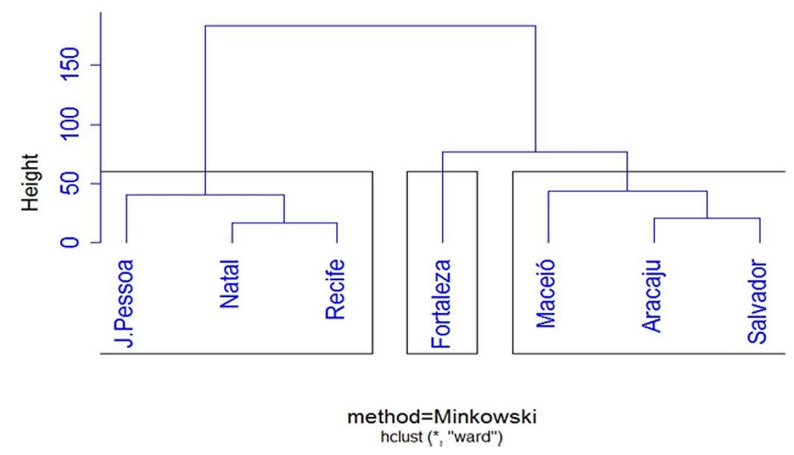

Figure 6. Dendrogram of clusters based on Total Ozone, AOD and intensity and Wind direction.
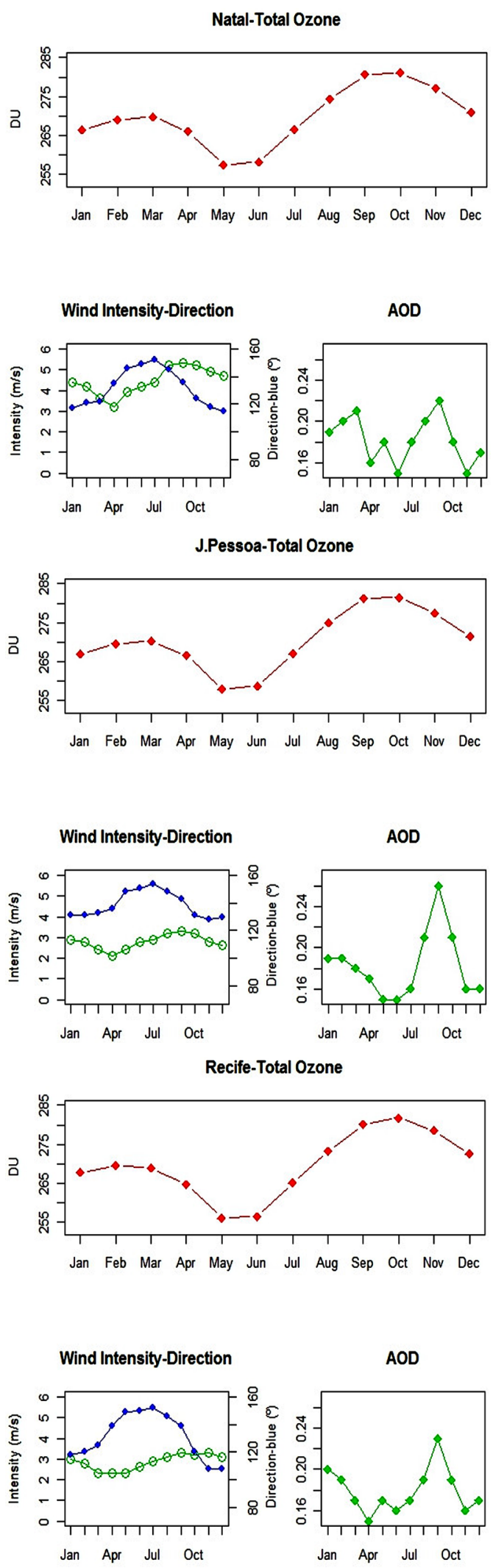

Figure 7. Total Ozone, intensity and Wind direction (blue color) and AOD for Group 1. 
The second group, formed by Maceió, Aracaju and Salvador, indicates that AOD and Wind characteristics and variability of Total Ozone are distinct to the first group, therefore, the stabilization of UV levels should not occur during this period and without proper measurement it is not possible to say if it occurs.

The last group was formed by a single city, Fortaleza, located in a distinct point on the northern coast of NEB. The data shows no similarity to that of the other cities and does not allow for a generalized conclusion about UV variability.

\section{Final Considerations}

The results indicated that the AES-UV takes place between September and October, since the Pearson correlation coefficient indicated an inverse relationship between Total Ozone and UV index corresponding to - 0.5. Independent of sky conditions, the AES-UV happens when the Total Ozone reaches its absolute annual maximum. The event was not described in scientific literature and was identified by multispectral sensor of UV.

The AES-UV has a small influence of aerosols (marine type) due to a higher concentration in September, whose origin is the greatest strength of the Wind and its direction (southeast).

The cluster analysis allowed us to confirm that this event occurs in a similar way in cities of Recife and João Pessoa in terms of Total Ozone, AOD and intensity and Wind direction.

Finally, the results are particularly relevant to the cities on the east coast of northeast Brazil, because they highlight the high levels of UV in practically all the seasons of the year. This may explain in part the higher number of cases of NMSC in city of Natal and alerts us to need for preventive actions by the local population and the need to warn tourists of the imminent risk of MSC if they do not use proper protection, especially during the summer months.

\section{Acknowledgements}

This work was supported by the CNPq, National Council for Scientific and Technological Development, Brazil: “ATMANTAR”-MCTI/PROANTAR/CNPq (520182/2006-5) and “A Atmosfera Antártica, Conexões e Impactos Ambientais na América do Sul”, INCT-APA, MCTI/PROANTAR/CNPq (574018/2008-5).

The authors thank the researcher Neusa Paes Leme and Engineer Francisco Raimundo Silva of the INPE/ CRN for their guidelines and kindness in providing the data.

\section{REFERENCES}

[1] WHO, "Global Solar UV index: A Practical Guide,”
World Health Organization, World Meteorological organization (WMO), United Nations Environment Program (UNEP), and International Commission on NonIonising Radiation Protection (ICNRP), Geneva, 2002, 18 p.

[2] WMO, "Scientific Assessment of Ozone Depletion: 2010," World Meteorological Organization, Geneva, 2011.

[3] S. Madronich, "UV radiation in the natural and perturbed atmosphere,” In: M. Tevini, Ed., UV-B Radiation and Ozone Depletion, Lewis Publishers, London, 1993, pp. 17-69.

[4] K. N. Liou, “An Introduction to Atmospheric Radiation,” 2nd Edition, Academic Press, 2002.

[5] J. Sabburg and J. Wong, "The Effect of Clouds on Enhancing UVB Irradiance at the Earth's Surface: A One Year Study," Geophysical Research Letters, Vol. 27, No. 20, 2000, pp. 3337-3340. http://dx.doi.org/10.1029/2000GL011683

[6] S. Madronich and F. R. de Grujil, "Skin Cancer and UV Radiation,” Nature, Vol. 366, 1993, pp. 23-28.

http://dx.doi.org/10.1038/366023a0

[7] A. R. Webb and M. F. Holick, "The Role of Sunlight in the Cutaneous Production of Vitamin $\mathrm{D}_{3}$," Annual Review of Nutrition, Vol. 8, 1998, pp. 375-399.

http://dx.doi.org/10.1146/annurev.nu.08.070188.002111

[8] B. L. Diffey, “The Consistency of Studies of Ultraviolet Erythema in Normal Human Skin,” Physics in Medicine and Biology, Vol. 27, 1982, pp. 715-720. http://dx.doi.org/10.1088/0031-9155/27/5/006

[9] A. F. Parisi, A. Green and M. G. Kimlin, "Diffuse Solar Ultraviolet Irradiation and Implications for Preventing Human Eye Damage,” Journal of Photochemistry and Photobiology, Vol. 73, No. 2, 2001, pp. 135-139. http://dx.doi.org/10.1562/0031-8655(2001)073<0135:DS URAI $>2.0 . \mathrm{CO} ; 2$

[10] F. R. De Gruijl, "UV-Induced Immunosuppression in the Balance,” Journal of Photochemistry and Photobiology, Vol. 84, No. 1, 2008, pp. 2-9.

[11] BRASIL, Instituto Nacional de Câncer José Alencar Gomes da Silva (INCA), "Estimativa 2012-Incidência de Câncer no Brasil,” Ministério da Saúde do Brasil, Brasília, 2011.

[12] R. L. McKenzie, P. J. Aucamp, A. F. Bais, L. O. Björn, M. de Ilyasf and S. Madronichg, "Ozone Depletion and Climate Change: Impacts on UV Radiation,” Journal of Photochemistry and Photobiology, Vol. 10, No. 2, 2011, pp. 182-198. http://dx.doi.org/10.1039/c0pp90034f

[13] J. Lee-Taylor and S. Madronich, "Climatology of UV-A, UV-B, and Erythemal Radiation at the Earth Surface, 1979-2000,” National Center for Atmospheric Research Boulder, Colorado, 2007.

[14] J. R. Herman, “Global Increase in UV Irradiance during the Past 30 Years (1979-2008) Estimated from Satellite Data," Journal of Geometry and Physics, Vol. 115, No. D4, 2010, pp. 01-15.

[15] J. R. Herman, G. Labow, N. C. HSU and D. Larko, "Changes in Cloud and Aerosol Cover (1980-2006) from 
Reflectivity Time Series Using SeaWiFS, N7-TOMS, EP-TOMS, SBUV-2, and OMI Radiance Data,” Journal of Geometry and Physics, Vol. 114, No. D1, 2009, pp. 01-21.

[16] J. H. Seinfeld and S. N. Pandis, "Atmospheric Chemistry and Physics-From Air Pollution to Climate Change," 2nd Edition, John Wiley \& Sons Ltd., New York, 2006.

[17] A. A. Silva, "A Espessura óptica de Aerossóis na Banda do UV-B,” Ph.D. Thesis, INPE, São José dos Campos, 2002.

[18] BRASIL, IBGE, “Estimativa Populacional 2013,” Instituto Brasileiro de Geografia e Estatística, 2013.

[19] F. R. Silva, "Estudo da radiação ultravioleta na cidade de Natal-RN,” M.S.Thesis, Federal University of Rio Grande of Norte, Natal, 2008.

[20] BRASIL, Instituto Nacional de Meteorologia-INMET “Normais Climatológicas do Brasil 1961-1990,” Brasília, 2009.

[21] J. A. Neves, "Um índice de Susceptibilidade ao Fenômeno da seca para o Semiárido Nordestino,” Ph.D. thesis, Federal University of Pernambuco-UFPE, Recife, 2010.

[22] P. Nobre and A. B. C. Melo, "Variabilidade Climática intrasazonal sobre o Nordeste do Brasil em 1998-2000," Revista Climanálise, CPTEC/INPE, 2001.

[23] A. B. Lopo, M. V. M. Mata, R. L. Andrade, C. M. S. Silva, "Ciclo Diário de Precipitação Sobre a Cidade de Natal," Proceedings of The 16th Brazilian Congress of Meteorology, Belém, 13-17 September 2010.

[24] C. A. Nobre and L. C. B Molion, "The Climatology of Drought and Drought Prediction,” In: T. R. Parry, R. Carter and N. T. Konjin, Eds., The Impact of Variations on Agriculture. v.2: Assessments in Semi-arid Regions, Kluwer, Dordrech, 1988, pp. 305-323.

[25] E. Kalnay, M. Kanamitsu, R. Kistler, W. Collins, D. Deaven, L.Gandin, M. Iredell, S. Saha, G. White, J. Wollen, Y. Zhu, A. Letman, R. Reynolds, M. Chelliah, W. Ebisuzaki, W. Higgins, J. Janowiak, K. C. Moo, C. Ropelewski, J. Wang, R. Jenne and D. Josepf, "The NCEP/ NCAR 40-Year Reanalysis Project," Bulletin of the American Meteorological Society, Vol. 77, No. 3, 1996, pp. 437-471.

[26] A. F. MCkinlay and B. L. Diffey, “A Reference Action Spectrum for Ultraviolet-Induced Erythema in Human Skin,” In: Passchler and Bosnajokovic, Eds., Human EXposure to Ultraviolet Radiation: Risks and Regulations, Elsevier, Amsterdã, 1987, pp. 17-22.

[27] S. D. Wilks, "Statistical Methods in the Atmospheric Sciences,” 2nd Edition, Academic Press, San Diego, 2006.

[28] J. H. Ward, "Hierarchical Grouping to Optimize an Objective Function," Journal of the American Statistical Association, Vol. 58, No. 301, 1963, pp. 236-244. http://dx.doi.org/10.1080/01621459.1963.10500845

[29] C. R. Roy, H. P. Gies and S. Toomey, "Monitoring UV-B at the Earth's Surface,” Australian Meteorological Magazine, Vol. 46, No. 3, 1997, pp. 203-210.

[30] M. P. Corrêa and A. Plana-Fattori, “A Theoretical Analysis of the UV Index Variations in Relationship to the Ozone Content and Aerosol Optical Depth Observations in São Paulo City,” Brazilian Journal of Meteorology, Vol. 21, No. 1, 2006, pp. 24-32.

[31] M. Horváth, L. Bilitzky and J. Huttner, “Ozone,” Elsevier, New York, 1985.

[32] M. P. Corrêa, P. Dubuisson and A. Plana-Fattori, "An Overview of the Ultraviolet Index and the Skin Cancer Cases in Brazil," Journal of Photochemistry and Photobiology A, Vol. 78, No. 1, 2003, pp. 49-54. http://dx.doi.org/10.1562/0031-8655(2003)078<0049:AO OTUI>2.0.CO;2

[33] Y. Sahai, V. Kirchhoff and N. P. Leme, "Total Ozone Column Trends in the Tropics", Journal of Geometry and Physics, Vol. 105, No. D15, 2000, pp. 19823-19823.

[34] V. E. Fioletov, J. B. Kerr and D. I. Wardle, "The Relationship between Total Ozone Column and Spectral UV Irradiance from Brewer Observations and Its Use for Derivation of Total Ozone Column from UV Measurements," Geophysical Research Letters, Vol. 24, No. 23, 1997, pp. 2997-3000. http://dx.doi.org/10.1029/97GL53153

[35] J. Van Geffen, R. Van der A, M. van Weele, M. Allaart and H. Eskes, "Surface UV Radiation Monitoring Based on GOME and SCIAMACHY," Proceedings of the ENVISAT \& ERS Symposium, Salzburg, 6-10 September 2004.

[36] J. H. Seinfeld and S. N. Pandis, "Atmospheric Chemistry and Physics-From Air Pollution to Climate Change," 2nd Edition, John Wiley \& Sons Ltd., New York, 2006.

[37] M. Z. Jacobson, "Fundamentals of Atmospheric Modeling," Cambridge University Press, New York, 2005. http://dx.doi.org/10.1017/CBO9781139165389

[38] M. A. Yamasoe, P. Artaxo, A. H. Miguel and A. G. Allen, "Chemical Composition of Aerosol Particles from Direct Emissions of Vegetation Fires in the Amazon Basin: Water-Soluble Species and Trace Elements,” Atmospheric Environment, Vol. 34, No. 10, 2000, pp. 1641-1653. http://dx.doi.org/10.1016/S1352-2310(99)00329-5

[39] S. Watanabe, T. Takemura, K. Sudo, T. Yokohata and H. Kawase, "Anthropogenic Changes in the Surface All-Sky UV-B Radiation through 1850-2005 Simulated by an Earth System Model,"Atmospheric Chemistry and Physics, Vol. 12, No. 11, 2012, pp. 5249-5257. http://dx.doi.org/10.5194/acp-12-5249-2012 